\title{
Algunas notas sobre el Derecho Comercial Bancario
}

\author{
Por el Dr. CARLOS CAMPRUBI ALCAZAR \\ Catedrático de la Universidad Católica
}

Se ha incorporado recientemente al plan de estudios universitarios una nueva disciplina jurídica denominada "Derecho Comercial Banca. rio". Por la materia que es su objeto representa una rama del derecho mercantil, con características propias derivadas de la especial naturaleza de los negccios bancarios. Justifican plenamente la importancia de su estudio, la significación profesional que tiene, y el progreso alcanzado por la clase de relaciones que regula.

Como es sabido, el Perú hasta hace muy poco no tuvo un régimen jurídico especial aplicable con carácter de excepción, al tráfico bancario. El Código de Comercio contenía solamente unas cuantas y diminutas normas referentes a bancos, que fueron modificadas y ampliadas en determinado sentido por disposiciones posteriores ocasionalmente dictadas. Sin embargo, éstas últimas no representaron una reforma integral y órganica de la materia, sino más bien una reglamentación, sin base técnica, de aspectos aislados y dispersos de la realidad jurídico-económica planteada por las operaciones de banca. Este estado de cosas se hallaba condicionado, evidentemente, por el incipiente desarrollo económico y financiero de épocas pasadas y por la influencia, en la actividad mercantil, de aquellos principios que dejaban a $\mathrm{l} a$ concurrencia individual y particular todas las rela. ciones comerciales y bancarias y que alejaban o reducían al mínimo la intervención reguladora y controladora del Estado. En efecto, el Código de 1853 y el vigente de 1902 -actualmente estrecho e inadecuado- se inspiraron en las doctriras individualistas surgidas en Furopa a principios del siglo XiX. las mismas cue se proyectaron en e! mundo por largo tiempo.

La complejidad de la vida moderna, ha infuldo decisivamente en la evolución del derecho, que, marcadamente, tiende a la especialización. El florecimiento de la legislación bancaria, dotada de caracteres propios y típicos, constituiría un nuevo fracrionamiento del derecho, destinado a protejer y encauzar dentro de moldes juridicos un género especial de relaciones humanas. El sistema jurídico aplicable a los bancos, aparece en el Perú en el año 1931 con la promulgación de la "Ley General de Bancos" y otras disposiciones conexas (Ley Orgánica del Banco Central de 
Reserva del Perú y Ley Monetaria). En su dación influyeron una serie de circunstancias, bastando señalar, por la indole divulgadora de estas líneas, tan solo unas cuantas. En primer lugar, el persamiento ya arraigado desde mucho ances de 193i, sobre la primacia del interés social frente al interés individual, justificativo de la intervención estatal; en segundo tér" mino, el progreso alcanzado por el país en cirterentes órdenes; siguiendo, la urgente necesidad de afrontar los problemas surgidos de la grave crisis económica de 1929 a 1932; y por último, la conveniencia de asegurar y garantizar el normal desenvolvimiento de los negocios bancarios, en beneficio de los intereses del público tan hondamente comprometidos en la gestión que los bancos llevan a cabo. La Exposición de Notivos del proyecto de la ley bancaria expresaba que "el público tiene especial interés en la reglamentación y supervigilancia de los bancos, ya que eśas empresas dependen principalmente para la obtención de fondos de los depósitos del público en general".

Sin embargo, no puede considerarse al Derecho Comercial Bancario como una disciplina autónoma en sentido estricto porque los principios que lo informan son comunes a otras ramas jurídicas y sus instituciones lo son, específicamente, de derecho mercantil. El Derecho Comercial Bancario es pues una derivación del derecho del comercio y de los comerciantes. Dentro de este orden de ideas, es evidente que dicha disciplina juridica tiene como materia las relaciones surgidas de aquellos institutos de crédito que, favoreciendo la circulación de la riqueza y realizando una función importante en la economía, persiguen un lucro, un beneficio particular también económico. Pero hay institutos bancarios en los que el lu. cro como finalidad fundamental de sus actividades se diluye, dando paso a objetivos de bienestar general. Estos bancos son aquellos mediante los cuales el Estado, por ser insuficiente en necesaria medida la iniciativa privada, promueve la satisfacción de un servicio público o el conveniente desarrollo de determinado sector de la riqueza del país con miras de bien social. Las relaciones emanadas de estos institutos estarían alejadas, consecuentemente, de la materia propia del Derecho Comercial Bancario porque la gestión que lleven a cabo responde a fines de índole distinta de la mercantil. Las nociones de lucro y de bien social sirven de base, pues, para definir concretamente la naturaleza jurídica de las actividades de una y otra clase de entidades bancarias y también para trazar una línea divisoria entre los estatutos legales aplicables. En nuestro medio, tales entidades se hallan representadas por los llamados bancos "comerciales" y los denominados de "fomento" o"especiales", siendo un ejemplo de los primeros el "Banco de Crédito del Perú", y de los segundos el "Banco 'Agrícola del Perú".

El nombre "Derecho Comercial Bancario" se ajusta a la clase de relaciones que regula, pero, por razones de claridad, conviene distinguirlo del título "Legislación Bancaria". Este último representa, en efecto, un concepto genérico que comprende a todas las leyes referentes a bancos en general; mientras que el adoptado de "Derecho Comercial Bancario", específicamente corresponde al conjunto de disposiciones legales aplicables a los bancos que desarrollan una actividad mercantil o comercial. En este sentido, el Derecho Comercial Bancario constituye una parte de la "Legislación Bancaria". pero, con relación a sistemas jurídicos definidos y más generales, es una derivación del Derecho Comercial por ser análogos 
los principios que sustentan y comunes las instituciones que tienen. De acuerdo con estos conceptos, el Derecho Comercial Bancario tendria su expresión positiva en el estatuto legal conocido entre nosotros con el nombre de "Ley de Bancos".

Es por las variadas y múltiples situaciones que reglamenta y por el plan técnico y lógico adoptado en su conformación, que la Ley de Bancos tiene una fisonomía muy peculiar, lo cual daría base para calificarla, usando términos de Du Pasquier, como una "rama compleja" del derecho. En efecto, es en la Ley de Bancos donde se entrecruzan y conectan una serie de disposiciones que interesan y lo son de otras disciplinas jurídicas, pero que su incorporación dentro de dicho régimen es indispensable para lograr, eficazmente, los fines que le son propios. Asi por ejemplo, y esto es una novedad en nuestro medio, los bancos han sido facultados en forma expresa para ejercer funciones de guardadores de bienes de menores, de incapaces y de ausentes. y otras como las de administradores de bienes comunes, de herencias, etc; relaciones todas ellas de naturaleza netamente civil. Dentro de otro aspecto, al proveer la Ley de Bancos la organización y funcionamiento del servicio del control y supervigilancia por el Estado (Superintendencia de Bancos) de las empresas bancarias, se está frente a reglas de derecho administrativo. No podríamos dejar de señalar, también, aquellas que, al determinar la noción jurídica de la nacionalidad de los barcos para los efectos de las restriccionee derivadas de la condición de extranjeros. pertenecen al derecho internacional privado. $Y$ no es menos destacable, dentro del mismo genero de observaciones, el aspecto de la ley en lo referente a la definición y enumeración de las "faltas" de los bancos y a la aplicación de a técimen especial de sanciones; sin ser estas disposiciones de derecho penal estricto, es evidente que lo son de una rama emparentada, cual es la ya conocida con el nombre de "Derecho Penal Administrativo" o "Derecho Disciplinario", tanto por la naturaleza de las "faltas" y por la clase de sanciones que establece cuanto por ser un organo del Estado -que no es el Poder Judicial- el que las aplica y hace efectivas. Desde un punto de vista más general, la Ley de Bancos no solamente contiene reglas de derecho sustantivo como son las que determinan los derechos, obligaciones y prohibiciones de las empresas bancarias; también dicta las necesarias para los casos de liquidación y quiebra de sus negocios; lo cual significa, estrictamente, puro derecho adjetivo o procesal. Igual apreciación merecen por ejemplo las reglas que señalan el procedimiento a seguir para la enajenación. en caso de obligaciones vencidas, de las prendas bancarias. Y sería muy largo seguir apuntando las demás características que le dan a la Ley de Bancos esa fisonomía peculiar que tiene. Obvio es destacar entonces, porque saltan a la vista, las profundas vinculaciones que el Derecho Comercial Bancario tiene con otras disciplinas jurídicas, demás leyes sobre bancos y con las ciencias sociales que le dan un fundamento $y$ una razón de ser.

En cuanto a la forma como funciona el sistema jurídico aplicable, la organización y operaciones de las empresas bancarias comerciales están regidas por la Ley de Bancos, conforme a la cual deben formular sus correspondientes estatutos. En forma complementaria y para todo lo no previsto rige el Código de Comercio. Son de aplicación en seguida los usos $y$ costumbres en materia mercantil y bancaria $\mathrm{y}$ por último las disposiciones de! derecho común. En materia bancaria es importante la intervención 
de los usos y costumbres como base reguladora de ciertos contratos y operaciones; basta mencionar el caso del depósito bancario (no nos referimos al depósito en custodia), cuya naturaleza jurídica rebasa en cierto modo He las pautas señaladas por el Código de Comercio para el depósito mercantil y lo convierte en una operación en gran parte regida por la costumbre. Igualmente, respecto a la facilidad que los bancos prestan a sus clientes para mantener cajas de seguridad en su local, etc. etc.

Considerando su aspecto formal, la Ley de Bancos comprende nueve capítulos, precedidos de la correspondiente Exposición de Motivos que facilita la recta interpretación de las disposiciones legales aplicables. Cada uno de dichos capítulos son, sucesivamente, (1) "Superintendencia ide Bancos", (II) "Establecimiento de empresas bancarias nacionales y de sucursales de bancos extranjeros". (III) "Organización y operaciones de bancos comerciales", (IV) "Cajas y Secciones de Ahorros", (V) "Comisiones de Confianza", (VI) "Inspección de empresas bancarias", (VII) "Imposición de Multas", (VIII) "Liquidación de empresas bancarias y (IX) "Disposiciones diversas". Sin embargo, pese a su extensión, la ley no abarca todos los detalles posibles de las operaciones bancarias. En esta materia, tal vez como en ninguna otra, se producen continuas variaciones dentro de sus condiciones, por lo que y siendo necesario amoldar a dicho cambios las prácticas bancarias, la Ley de Bancos ha "fijado reglas generales, dejando al Superintendente de Bancos la determinación de los detalles por medio de reglamentaciones administrativas" (Exposición de Motivos). Esto permite, pues, una ajustada adecuación de la ley a la realidad y asegura el conveniente funcionamiento del estatuto legal en todos los casos que surgen por razón de la natural evolución que experimentan los negocios bancarios.

Dentro de la misma ley hay que distinguir disposiciones de caracter general y de caracter especial, esto es, normas aplicables sin excepción - salvo cuando la misma ley expresamènte determina lo contrarioa todas las empresas bancarias y normas aplicables solamente a los llamamados bancos comerciales y de ahorros y a las cajas de ahorros (La Caja de Ahorros de la Sociedad de Beneficencia Pública de Lima, que realiza operaciones típicamente bancarias, no está comprendida, de conformidad con la Ley 7635, dentro de las disposiciones de la Ley de Bancos, sino que funciona con arreglo a sus propios estatutos, cuyo cumplimiento vigila la Superintendencia de Bancos mediante las visitas de inspección), Entre las primeras se hallan los capítulos II, VI, VII VIII y IX y entre las segundas los capítulos III, IV y V; siendo el capítulo I el que establece todo lo necesario para la organización y funcionamiento de la Superintendencia de Bancos, entidad administrativa prevista por la Constitución del Estado (Art. 13\%) y encargada del control y supervigilancia de las empresas bancarias en general.

Debe hacerse mención, al tratar estos aspectos, del 'sistema de definiciones usado por la Ley de Bancos en varias de sus figuras y relaciones, sistema contrario al adoptado por nuestra legislación civil y al que está siguiendo la Comisión Reformadora del Código de Comercio en la elaboración del proyecto respectivo. Dentro de un régimen jurídico especial-como lo es la ley bancaria - es indudable que el sistema de las definiciones trae ventajas, porque precisa los alcances y la adecuada aplicación de sus normas. Y es la práctica la que ha evidenciado la utilidad 
y la conventencia de sisiema usado. De este modo la ley de Parcos ha meonomio en su cero, para los efectos corospondentes, la definición de es conceptos: "empresa bancava, batno comercial", "capital líquido", "obligarones con el públeo", "oblgacones a la vista", "obligaciores a piazo", "uilidades liquidas", etc . etc.

Entre las figuras tiplcae y propias de Derecho Comercial Bancario puecien citase, por via de ejempio, El cepósto bancerio, que en una categone particuat del depósito mercantil el depcsio de ahoro, que es una especiásima rarante ciel depósito bancario con la característica pecular de en inembargabijdad; la prescripción que se ha dado en lamar "bancaria" y que beneficia a las Sociedades de Beneficencia Fública y al Entan según os casos las comiones de confianza, figura sui generis y novedosa en nuestro medio, que representa un ejemplo concreto de influencia juxidina arglo américana. pero aduptacia a las modalidades del derecho nacional; as prendas bancarías (garantias); las faltas y penas de los bancos; la liquidacion vointaria o forzosa, de las empresas bancarias; etc etc. Ciertamente estas cuestiones, que son solamente unas cuantas, no agotan la vasta materia que es objeto de la discipina jurídica recientemente incorporada al fian de estudios universitarios.

Todas las generalidades anotadas tienen solamente un fin de divulgación. Hasta ahora, casi ningún examen y estudio ha merecilo la realidad bancaria del país en el triple aspecto que presenta: económico, técnico y jurídico. Igual cosa podría decirse con relación a su historia, que de por si es muy sugestiva. Lo poco que existe, en este último asperto, o son referencias incidentales hechas en tratados generales de historia nacional o en ensayos y monografías sobre historia económica o son estudios que comprenden una sola faz del desenvolvimiento bancario del país. Y esto, en verdad, no es bastante para conocer debidamente el pasado peruano en este aspecto.

Mi preferencia por estos tópicos me ha inducido a preparar un trabajo sobre la materia, que, evidentemente, no tendrá la pretensión de agotarla ni darie caracteres de tratado, pero si la de aportar - con buena voluntad - algo que puede ser útil al estudio y mejor conocimiento de nuestra realidad bancaria. 